DIMENSI, VOL. 6, NO. 1: 77-89

JANUARI 2017

ISSN: 2085-9996

\title{
ANALISA BEBAN KERJA DAN PENGEMBANGAN PERSAMAAN PREDIKSI KONSUMSI OKSIGEN PADA MAHASISWA PEKERJA INDUSTRI (STUDI KASUS MAHASISWA TEKNIK INDUSTRI UNIVERSITAS RIAU KEPULAUAN)
}

\section{WORKLOAD ANALYSIS AND DEVELOPMENT OF PREDICTIVE MATHEMATICAL MODEL OXIGEN CONSUMPTION IN STUDENTS INDUSTRY WORKERS (A CASE STUDY : INDUSTRIAL ENGINEERING STUDENTS OF RIAU KEPULAUAN UNIVERSITY)}

\author{
Benedikta Anna Haulian Siboro', Vera Methalina Afma² \\ ${ }^{1,2}$ Program Studi Teknik Industri, Universitas Riau Kepulauan, Batam, Indonesia \\ 1b.anna79@gmail.com1, ${ }^{2}$ vera.afma@gmail.com
}

\begin{abstract}
Abstrak
Penelitian ini bertujuan untuk menganalisa, mengevaluasi beban kerja pada mahasiswi pekerja serta mengembangkan persamaan prediksi konsumsi oksigen pada pekerja tersebut.Mayoritas mahasiswa di Teknik Industri Universitas Riau Kepulauan Batam adalah pekerja yang kebanyakan bekerja di industri elektronik dan galangan kapal dengan jenis pekerjaan yang berbeda-beda. Pada penelitian ini, variabel yang akan diteliti adalah beban kerja yang dilakukan pada pekerja apakah masih dalam batas normal serta mengembangkan persamaan konsumsi VO2 bagi masing-masing jenis pekerjaan tersebut dengan melakukan penelitian menggunakan sepeda ergonometer (submaximal test) dan pengangkatan beban secara manual(manual material handling). Data-data yang didapat dari pengambilan data denyut jantung, serta data kesehatan mahasiswa pekerja ini nanti diolah dan dicari persamaan prediksinya menggunakan metode statistic seperti uji independensi error, Uji multikolinearitas antar variable independen dan metode stepwise Hasil penelitian menunjukkan dari 240 mahasiswa, 80\% mahasiswi bekerja di elektronika sedangkan sisanya di bidang lain dan tidak bekerja. Selain itu juga pada pengukuran submaksimal menggunakan sepeda ergocycle menunjukkan pada menit ke-8 terjadi penurunan denyut jantung dan begitu juga pada pengangkatan benda secara terjadi penurunan heart rate pada menit ke-10 dan diklasifikasikan dalam pekerjaan ekstrim. Selain itu juga ada hubungan antara VO2 maksimum dengan heart rate sehingga didapat persamaan VO2 Max $=11.531-0.056 x$ heart rate (submaximal test) dan VO2 max $=23.910-0.141 \times$ heart rate ( manual material handling)
\end{abstract}

Kata kunci : konsumsi VO2, submaximal test, manual material handling, heart rate

\begin{abstract}
The purpose of this research are analysis and evaluation workload of students industry workers including to develop predictive mathematical model of oxygen consumption this workers. Majority of Industrial Engineering student at Riau Island Univeristy - Batam are workers who mostly worked in the electronics industry and shipbuilding with different kind of work.In this research, the variables to be studied is workload which is done on whether the worker was within normal limits and develop VO2 consumption equation for each of these jobs by doing research using bike ergonometer (submaximal test) and doing manual handling. The data obtained from recording of the heart rate, as well as student worker health data is later processed and searched the prediction equation using statistical methods such as the independence of the error test, test multicollinearity between independent
\end{abstract}


variables and stepwise method. The results showed from 240 students, $80 \%$ of student work on the electronics manufacturing and the rest in other areas and do not work. In submaximal test using Ergocycle bike show that heart rate value decrease in the 8th minute and for manual material handling decrease in $10^{\text {th }}$ minute. These activities classified to extreme works decrease in heart rate and so is the removal of objects in a decrease in heart rate in the 10th minute and classified in extreme jobs. There was also a correlation between VO2 maximum and heart rate in order to get the equation VO2 Max $=11.531-0.056 x$ heart rate (submaximal test) dan VO2 max $=23.910-0.141$ $x$ heart rate (manual material handling)

Key words : VO2 consumption, submaximal test, manual material handling, heart rate

\section{PENDAHULUAN \\ Latar Belakang}

Batam sebagai salah satu kota industri memiliki ratusan industri besar yang biasanya menjalankan usahanya di dalam kawasan-kawasan industri yang banyak berdiri di Batam. Kawasan-kawasan terbagi dalam beberapa kelompok yang menghasilkan produk sejenis seperti kawasan industri elektronik. Industri shipyard (galangan kapal). industri pipa/supporting part. industri rigging untuk pengeboran minyak. Masing-masing jenis industri besar ini memiliki beban kerja yang berbeda-beda. Untuk industri dengan jenis usaha elektronik sebagian besar karyawan adalah wanita. dan jenis usaha lainnya sebagian besar adalah pria.

Permasalahan muncul apabila beban pekerjaan (demand) dan kapasitas manusia (capacity) yang tidak seimbang. hal ini sangat beresiko besar terjadinya kelelahan kerja dan pada akhirnya akan terjadi kesalahan kerja atau kecelakaan kerja. Oleh karena itu dalam mendesain suatu pekerjaan dan peralatan kerja perlu memperhatikan demand dan capacity manusia. Cara agar beban pekerjaan tidak melebihi kapasitas kerja manusia adalah dengan mengetahui berat ringannya beban kerja dan mengukur aktivitas kerjanya. Salah satu pendekatan yang digunakan adalah dengan menggunakan indikator konsumsi oksigen (VO2).

Menurut Leyland dalam Sukawati (2010) nilai VO2 merupakan gambaran aktivitas dari kemampuan paru-paru mengambil oksigen. kemampuan jantung memompa darah. kemampuan hemoglobin mendistribusikan oksigen. Kemampuan otot mendapatkan suplai oksigen dan kemampuan mitokondria serta enzim tubuh untuk menghasilkan energi sehingga pengukuran konsumsi oksigen ini dapat menggambarkan organ-organ tersebut dalam satu integritas.

International Labour Organization (ILO) dalam Hasibuan ( 2005) mengatakan bahwa secara lebih sederhana maksud dari produktivitas adalah perbandingan secara ilmu hitung antara jumlah yang dihasilkan dan jumlah setiap sumber yang dipergunakan selama produksi berlangsung. Sumber tersebut dapat berupa tanah, bahan baku pabrik, mesin dan tenaga kerja. Faktor sumber daya manusia ini merupakan elemen yang harus diperhatikan oleh perusahaan terutama bilamengingat bahwa era perdagangan bebas akan segera dimulai dimana iklimkompetisi yang dihadapi akan sangat berbeda.

Menurut Sinungan (2005) terdapat dua kelompok syarat bagi produktivitas sumber daya agar SDM (sumber daya manusia) perorangan tinggi:

1. Kelompok pertama

a. Tingkat pendidikan dan keahlian

b. Jenis teknologi dan hasil produksi

c. Kondisi kerja

d. Kesehatan. kemampuan fisik dan mental

2. Kelompok kedua

a. Sikap mental (terhadap tugas). teman sejawat dan pengawas 
b. Keaneka ragam tugas

c. Sistem insentif (sistem upah dan bonus)

d. Kepuasan kerja

Pada persyaratan kelompok 1 terkandung faktor kesehatan pekerja yang juga akan mempengaruhi kualitas dari produktivitas tersebut. Dalam hubungan antarakesehatan dan produktivitas kerja terdapat faktor-faktor yang mempengaruhinya antara lain:

a. Beban Kerja

Setiap pekerjaan merupakan beban bagi pelaku kerja. Beban kerja mencakup beban fisik ( mengangkat. memikul. dan lain-lain). Beban mental (tanggung jawab bawahan terhadap atasan). beban social

b. Beban tambahan dari lingkungan kerja

Beban tambahan ini mencakup lingkungan fisik kerja seperti kebisingan, suhu. tekanan udara. penerangan dan getaran

c. Kapasitas kerja

Kapasitas kerja seseorang dipengaruhi oleh keterampilan. Kesehatan jasmani dan rohani. keadaan kesehatan, tingkat gizi, jenis kelamin,umur, ukuran-ukuran tubuh.

Ketiga faktor diatas harus berada dalam keseimbangan yang serasi agar didapat derajat kesehatan yang optimal dan produktivitas yang tinggi.

\section{Ergonomi dan Fisiologi Kerja}

Untuk memudahkan pemahaman mengenai ergonomi. maka ruang lingkupnya terdiri atas beberapa bagian :

a. Ergonomi Fisik : berkaitan dengan anatomi tubuh manusia, antropometri, karakteristik fisiologi dan biomekanika yang berhubungan dengan aktifitas fisik

b. Ergonomi kognitif : berkaitan dengan mental manusia seperti persepsi, ingatan,reaksi sebagai hasil akibat dari interaksi manusia terhadap elemen didalamnya

c. Ergonomi organisasi berkaitan dengan optimasi sistem. struktur oganisasi dan proses

d. Ergonomi lingkungan yang berkaitan dengan pencahayaan, temperatur, kebisingan. dan getaran.

Beberapa metode didalam lingkungan kerja dipakai untuk menilai keergonomisan suatu lingkungan kerja antara lain :

a. Diagnosis dengan melakukan wawancara.inspeksi terhadap kondisi lingkungan kerja

b. Treatment dilakukan dengan membuat perlakuan-perlakuan khusus dan melihat reaksi dari perlakuan yang dibuat

c. Follow up dengan melakukan evaluasi yang subyektif atau obyektif mengenai kenyamanan dan atau ketidaknyaman yang ditimbulkan seperti nyeri. kepala pusing,dan lain-lain.

Fisiologi kerja merupakan salah satu ilmu yang mempelajari bagaimana kinerja atau fungsi tubuh dan komponen-komponennya. Menurut Astrant dkk (2003) tujuan dari fisiologi kerja adalah mempelajari kinerja seseorang dalam menyelesaikan pekerjaan tanpa mengalami kelelahan pada akhir hari kerja dan masih ada tenaga yang cukup agar pekerja dapat menikmati waktu luang akhir pekannya. 


\section{Kapasitas Kerja Fisik}

Dalam melakukan kerja fisiknya. terdapat proses kontraksi otot yang didukung oleh proses metabolisme oksidasi didalam sel otot. Beban kerja otot tersebut dinyatakan dengan banyaknya konsumsi oksigen dalam liter per menit. Dalam satu liter yang dikonsumsi sama dengan 5 kkal ( $20 \mathrm{~J}$ ) Salah satu indikator dalam mengevaluasi kapasitas kerja fisik adalah kapasitas aerobik maksimal atau maximal physical work capacity ( MPWC). Konsumsi maksimum oksigen (VO2 max) menggambarkan kemampunan seseorang dalam memperoleh oksigen. MPWC dapat diketahui dengan adanya kapasitas maksimu jantung dan paru-paru dalam mengirimkan oksigen ke otot-otot yang bekerja.Menurut NIOSH dalam Soleman (2009) MPWC rata-rata untuk pria sehat sekitar $15 \mathrm{kkal} /$ menit dan wanita $10.5 \mathrm{kkal} /$ menit.

Kapasitas aerobik maksimum dapat ditentukan dengan 2 metode yaitu :

a. Metode maximal test

Pada metode ini responden diminta mengerahkan semua kemampuannya untuk mencapai kapasitas aerobik maksimum seperti penggunaan treadmill. Pada metode ini. akan menghasilkan gejala kelelahan dan tanda-tanda lain seperti mual, pusing, sesak nafas bahkan pingsan.

b. Metode submaximal test

Responden tidak dipaksakan untuk mencapai kondisi maksimum sehingga dampak kelelahan. resiko dan bahayanya lebih rendah.

\section{Pengukuran beban kerja dan konsumsi oksigen}

Pengukuran energi yang dibutuhkan saat bekerja pada umumnya dapat dilakukan dengan pengukuran tidak langsung dengan menghitung jumlah oksigen yang digunakan per satuan waktu. Evaluasi nilai absolute kebutuhan energi setiap individu dengan mengklasifikasikan pekerjaan menurut jenisnya seperti dijelaskan pada tabel 1

Tabel 1 Kebutuhan energi untuk setiap klasifikasi pekerjaan - Kromer dalam Soleman (2009)

\begin{tabular}{|c|c|c|c|c|}
\hline \multirow{2}{*}{$\begin{array}{l}\text { Klasifikasi } \\
\text { Pekerjaan }\end{array}$} & \multicolumn{2}{|c|}{ Total energi ekspenditur } & \multirow{2}{*}{$\begin{array}{c}\text { Denyut jantung } \\
\text { (denyut/menit) }\end{array}$} & \multirow{2}{*}{$\begin{array}{c}\text { Konsumsi } \\
\text { oksigen } \\
\text { (1/menit) }\end{array}$} \\
\hline & (kJ/menit) & (kkal/menit) & & \\
\hline Ringan & $10-20$ & $<2.5$ & $\leq 90$ & $<0.5$ \\
\hline Sedang & $20-30$ & $2.5-5.0$ & $90-110$ & $0.5-1.0$ \\
\hline Berat & $30-40$ & $5.0-7.5$ & $110-130$ & $1.0-1.5$ \\
\hline \begin{tabular}{|l|} 
Sangat Berat \\
\end{tabular} & $40-50$ & $7.5-10$ & $130-150$ & $1.5-2.0$ \\
\hline Ekstrim Berat & $50-60$ & $>10$ & $150-170$ & $>2.0$ \\
\hline
\end{tabular}

Evaluasi beban kerja dapat juga dianalisa dengan mengukur denyut jantung seperti pada tabel 2.1 Semakin berat kerja fisik seseorang. Maka semakin berat juga kerja jantung yang diindikasikan dengan adanya kenaikan nilai denyut jantung.

Menurut Soleman (2009) ketika suatu pekerjaan dilakukan maka konsumsi oksigen merupakan tolak ukur pengukuran produksi metabolisme energi. Metode evaluasi konsumsi oksigen merupakan metode yang dapat diandalkan dalam proses metabolisme. Menurut Kroemer dkk (1997) rata-rata nilai energi. sama dengan 5 kkal/liter oksigen. Selain itu juga dengan menggunakan nilai dari normogram Astrand Ryhming dapat juga diprediksi penggunaan VO2. Normogram yang diberikan oleh peneliti ini adalah sebagai berikut: 


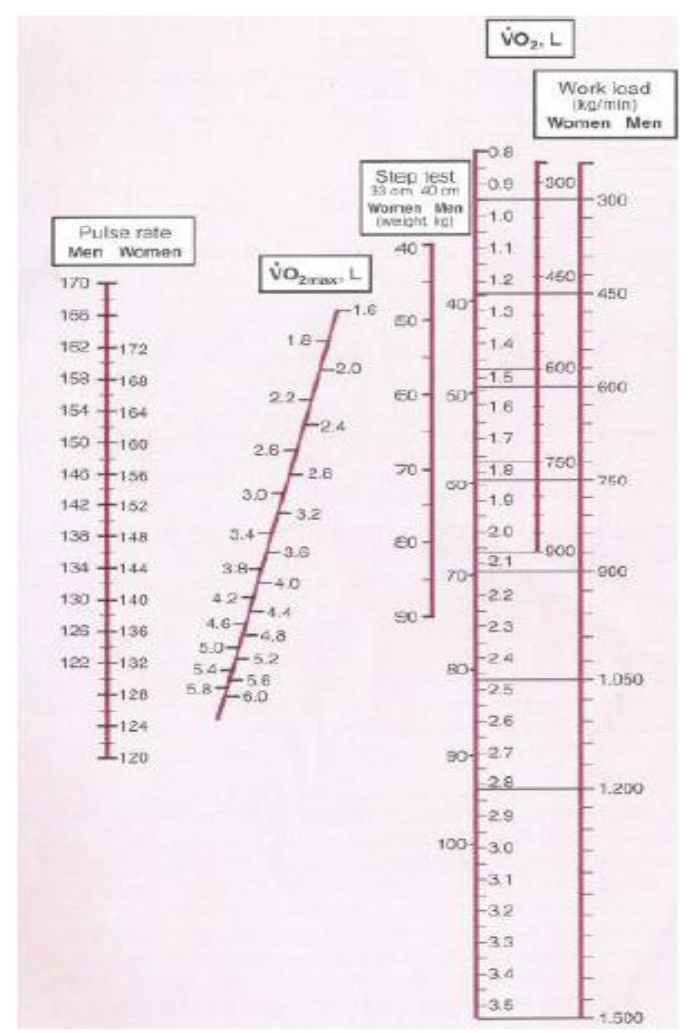

Gambar 1 Normogram Astrand-Ryhming

\section{Uji Statistik}

Terdapat beberapa penguji statistic yang digunakan pada penelitian ini yaitu:

1. Asumsi linieritas

Asumsi linieritas digunakan untuk mengetahui bahwa terdapat hubungan linier antara variable independen dan dependen (Hair. dkk. 2006).

2. Asumsi kenormalan

Uji asumsi kenormalan digunakan untuk menguji model regresi variabel-variabelnya memiliki distribusi normal (Hair. dkk. 2006). Pengujian asumsi normalitas error dilakukan secara visual dengan menggunakan histogram dan normal probability plot.

3. Uji independensi Error

Independensi error dapat diuji dengan statistic Durbin- Watson dimana digunakan untuk mengetahui autokorelasi dari variable independen yang akan pada penelitian ini.

4. Uji multikolinearitas antar variable independen

Uji ini bertujuan untuk mengetahui ada tidaknya korelasi antar variabel independen (Hair. 2006). Multikolinearitas antar variable dapat dilihat dari nilai statistic toleransi dan VIF ( Variance Inflation Factors). Model dikatakan tidak ada multikolinearitas antar variable jika nilai VIF kurang dari 10 artinya dan nilai toleransi sebuah regresi $>0.10$ 
5. Interpretasi hasil

Pengujian interpretasi hasil menggunakan metode stepwise. Regresi Stepwise merupakan salah satu metode untuk mengatasi adanya kasus multikolinieritas yaitu suatu kondisi dimana terjadi korelasi yang kuat diantara variabel-variabel independen. Dengan metode ini.akan didapat persaman regresi yang mencakup variable-variabel independen apa saja yang akan mempengaruhi konsumsi VO2.

\section{METODOLOGI PENELITIAN}

Lokasi penelitian dilakukan di Laboratorium Analisa Perancangan Kerja dan Ergonomi Teknik Industri Universitas Riau Kepulauan dengan objek penelitian ini adalah mahasiswa Teknik Industri yang mayoritas bekerja di industi elektronik dan galangan kapal. Obyek penelitian ini adalah mahasiswi (wanita) yang bekerja di elektronik dan galangan kapal.Berikut adalah diagram alir penelitian ini.

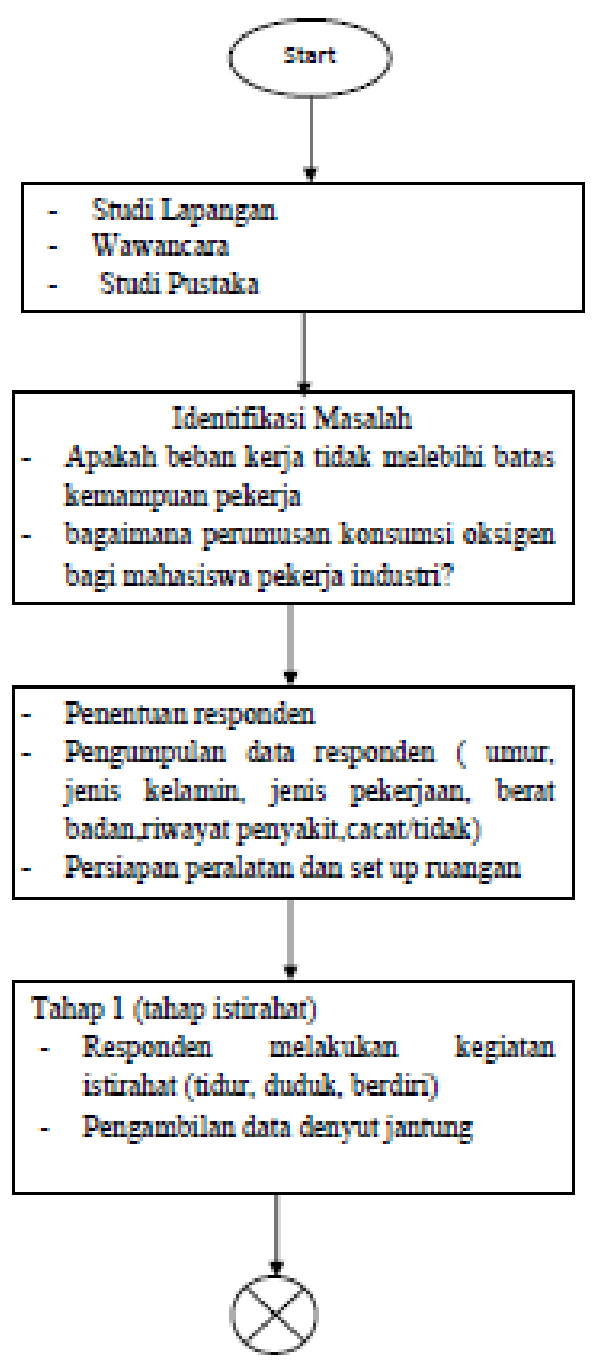

Gambar 2 Tahapan penelitian 


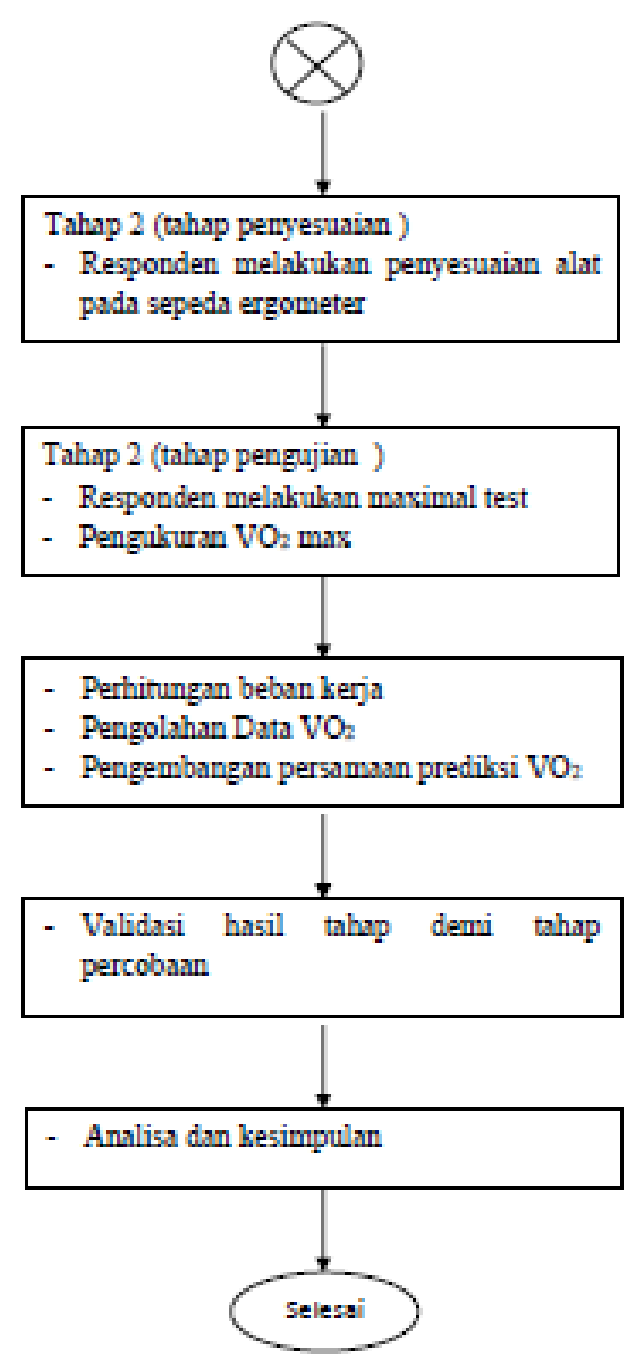

Gambar 2 penelitian (lanjutan)

Adapun variabel yang diamati dalam penelitian ini adalah :

\section{a. Variabel Dependen meliputi :}

1. Beban kerja yang dilakukan oleh pekerja

2. Konsumsi VO2 max yang terkandung dalam tubuh pekerja

b. Variabel Independen meliputi: Umur, Jenis pekerjaan pekerja, Berat badan, Riwayat kesehatan dan Lamanya waktu kerja

Penelitian ini memfokuskan pada jenis-jenis pekerjaan yang dilakukan oleh mahasiswa pekerja yang akan mempengaruhi beban kerja dan konsumsi VO2 pekerja itu sendiri. 


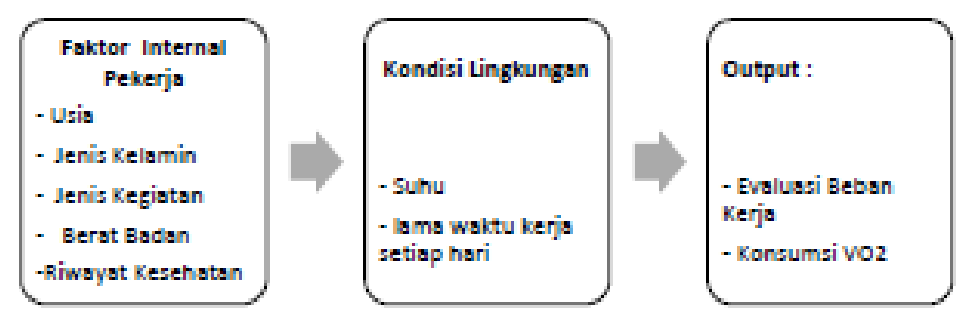

Gambar 3 Model Penelitian

\section{HASIL DAN PEMBAHASAN}

\section{Populasi Penelitian}

Populasi dalam penelitian ini adalah mahasiswi Teknik Industri Universitas Riau Kepulauan (UNRIKA). Populasi tersebut diambil dari 4 angkatan yaitu angkatan 2013, 2014 dan 2015 dan 2016 Jumlah dari seluruh mahasiswa (pria dan wanita) 4 angkatan tersebut ialah 240 orang. Dari jumlah tersebut hanya sekitar $80 \%$ nya bekerja di galangan kapal dan elektronika dan $20 \%$ lagi adalah bekerja di bidang industri lainnya dan ada yang tidak bekerja. Dari 240 total mahasiswa Teknik Industri terdapat 29 wanita (mahasiswi). Berikut ini adalah persentase mahasiswi (wanita) Teknik Industri setiap angkatan yaitu:

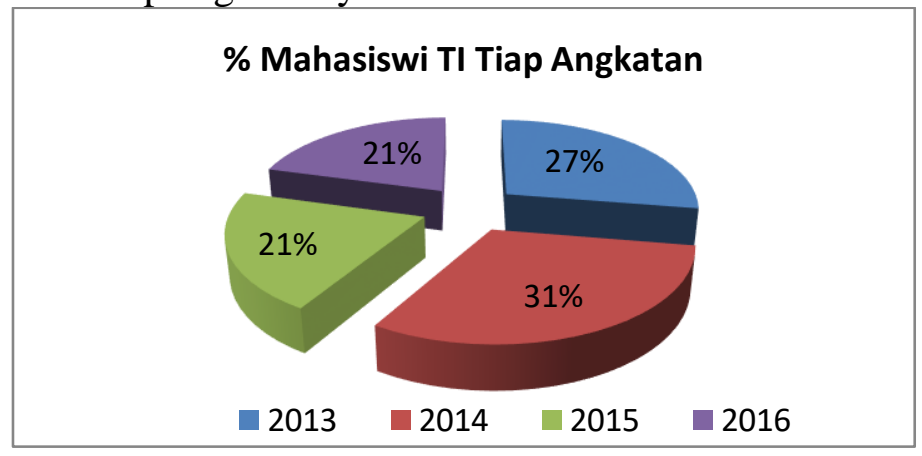

Gambar 4 Persentase Mahasiswi Teknik Industri Unrika

Dari 29 mahasiswi ditemukan sekitar 80\% mahasiswi bekerja dan kebanyakan bekerja di perusahaan elektronika. Berikut adalah persentase mahasiswi yang bekerja (dalam setiap angkatan). 24 mahasiswa (80\%) Teknik Industri (TI), 19 menjadi sampel dari penelitian ini dengan rentang usia sebagai berikut

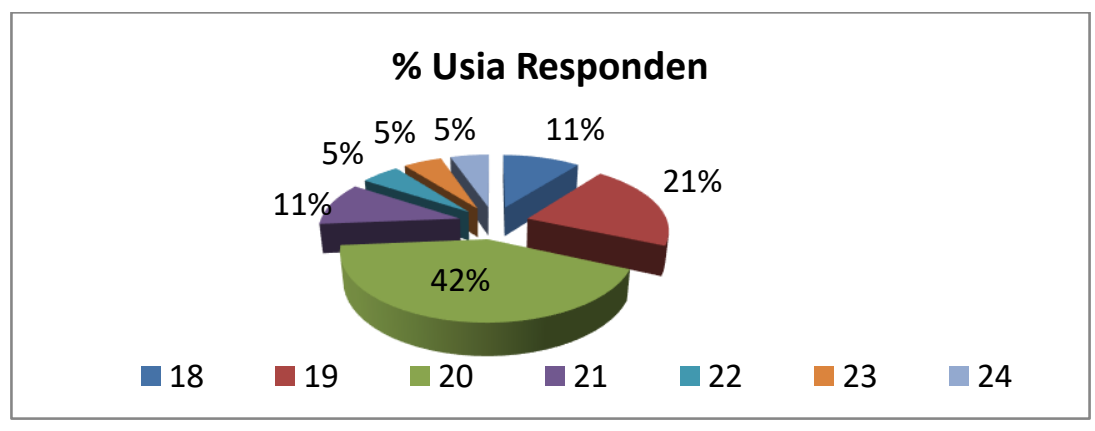

Gambar 5 Persentase usia masing-masing responden 
Dalam penelitian ini didapati bahwa data mayoritas yang diambil ialah banyaknya mahasiswi pekerja yang sudah bekerja lebih dari 0-3 tahun di elektronika maupun di perusahaan jasa lainnya.

\section{Aktivitas Konsumsi Oksigen}

\section{a. Submaximal test dengan mengayuh sepeda ergocycle}

Pada aktivitas ini mahasiswi diminta untuk mengayuh sepeda dengan dan tanpa beban denga durasi waktu 2 menit, 4 menit, 6 menit, dan 8 menit sehingga didapatkan denyut jantung per menit.

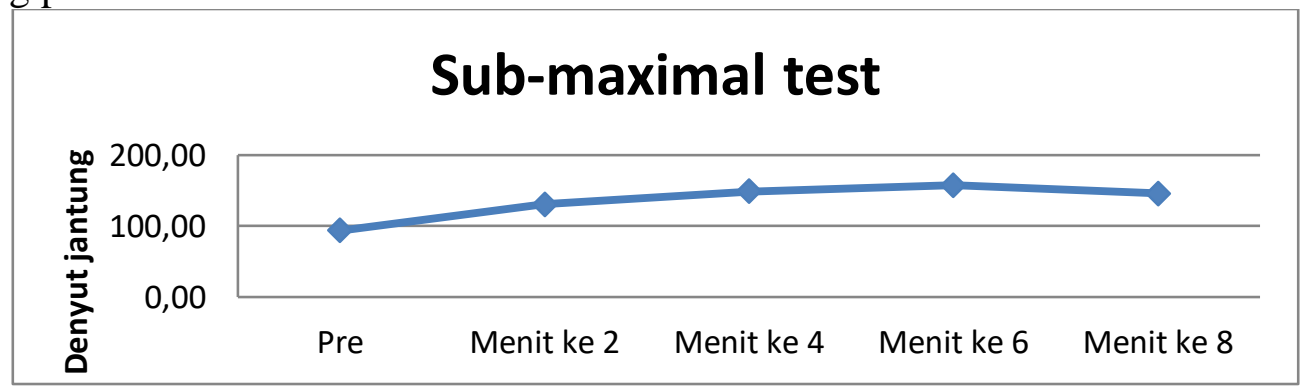

Gambar 6 Denyut nadi setiap dua menit pada kegiatan mengayuh sepeda

Pada kegiatan mengayuh sepeda ini, denyut nadi setelah dua menit mengalami peningkatan sampai pada menit ke-6. Namun pada menit ke-8 kemampuan jantung untuk beraktivitas berkurang sehingga denyut nadi berkurang. Prediksi VO 2 menggunakan teori Normogram Astrand-Ryhming dimana dari kegiatan ini rata-rata konsumsi VO2 maksimum adalah $2.68 \mathrm{~L} / \mathrm{min}$ dan berdasarkan tabel beban kerja maka diklasifikasikan sebagai pekerjaan ekstrim berat.

\section{b. Aktivitas Pengangkatan beban manual (manual material handling)}

Kegiatan ini dilakukan dengan mengangkat beban seberat $5 \mathrm{~kg}$ dari meja dan meletakkan kembali ke meja yang lain dengan jarak 3m serta dilakukan selama 10 menit. Pada pengangkatan benda secara manual menunjukkan bahwa terjadi penuruan nilai denyut jantung pada menit ke 10 .

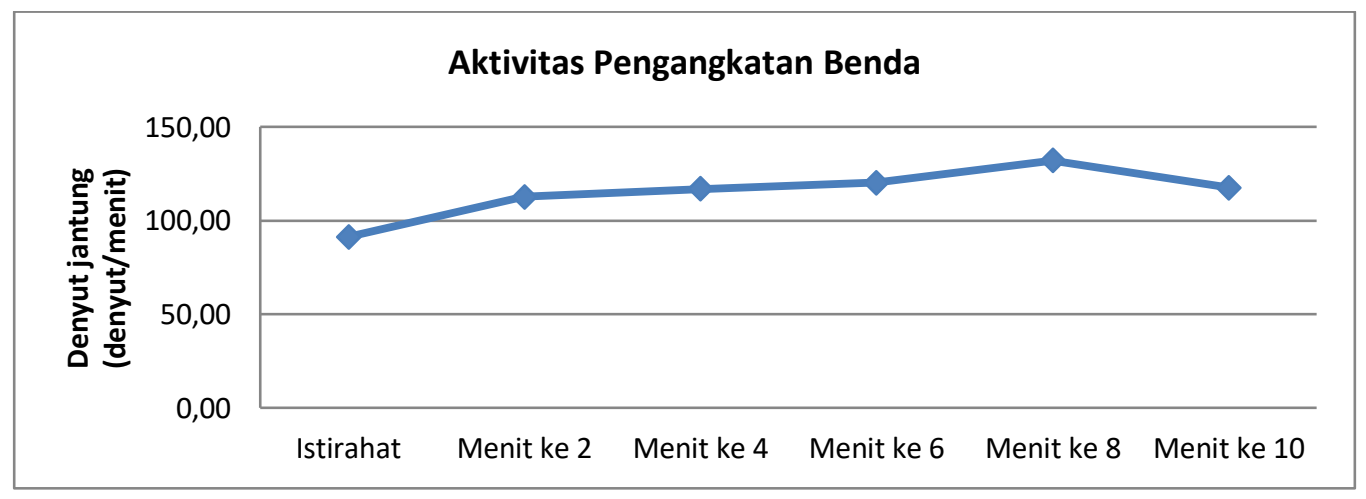

Gambar 7 Denyut nadi setiap dua menit pada kegiatan mengangkat benda 
Dengan menggunakan gambar Normogram Astrand-Ryhming maka diprediksi penggunakan VO2 max nya pada menit ke sepuluh rata-rata adalah $5.24 \mathrm{~L} / \mathrm{min}$ artinya diklasifikasikan sebagai pekerjaan yang ekstrim.

\section{Pengujian Statistik}

1. Uji Kenormalan

a. Submaximal test dengan mengayuh sepeda ergocycle

Dari hasil pengujian statistik untuk uji kenormalan data menunjukkan bahwa data tinggi badan, berat badan, heart rate dan VO2 max terdistribusi normal ( $>>0.05)$ dimana tinggi badan $=0.774$, berat badan $=0.615$, heart rate $=0.498$, dan VO2 max $=0.743$. Rata-rata nilai konsumsi VO2 $\max$ untuk mahasiswa pekerja industri elektronik $=2.68 \pm 0.498$ liter/menit.

b. Aktivitas Pengangkatan beban manual (manual material handling)

Dari hasil pengujian statistik untuk uji kenormalan data menunjukkan bahwa heart rate dan VO2 max terdistribusi normal ( $\mathrm{p}>0.05$ ) dimana tinggi badan $=0.338$, berat badan $=0.844$, heart rate $=0.715$, dan VO2 $\max =0.643$. Rata-rata nilai konsumsi VO2 $\max$ untuk mahasiswa pekerja industri elektronik pada proses manual material handling $=5.3 \pm 0.378$ liter/menit.

2. Asumsi Linearitas

Output SPSS untuk submaximal test dan aktivitas manual material handling menunjukkan bahwa hanya variabel heart rate yang mempunyai pengaruh signifikan terhadap nilai dari VO2 Max, sehingga hanya variabel heart rate saja yang nantinya akan masuk ke dalam model prediksi VO2 Max.

Tabel 2 Asumsi Linearitas

\begin{tabular}{llll}
\hline Variables Entered/Removed $^{\mathbf{a}}$ & & \\
\hline Model & Variables Entered & Variables Removed & Method \\
\hline 1 & HR & Stepwise $\quad$ (Criteria: \\
& & Probability-of-F-to-enter \\
& $<=.050$, Probability-of- \\
& & F-to-remove $>=.100)$. \\
\hline
\end{tabular}

a. Dependent Variable: VO2

3. Independensi error

Pengujian asumsi independensi error dapat dilakukan dengan menghitung nilai Durbin-Watson (d).Nilai Dw diperoleh berdasarkan jumlah sampel (n) yang digunakan dalam penelitian kali ini yaitu 12 sampel dan jumlah variabel independen berpengaruh (k) yaitu 1 buah (heart rate). Berdasarkan nilai d yang didapat dari tabel Durbin-Watson dengan nilai $\propto=0,05, \mathrm{n}=19, \mathrm{k}=1$ yaitu $\mathrm{dL}=1.18$ dan $\mathrm{dU}=1.401$. Ketentuan Durbin-Watson statistic adalah :

a. Tidak terdapat autokorelasi jika $\mathrm{dU}<\mathrm{d}<4$-dU sehingga batasnya adalah $1.401<\mathrm{d}<$ 2.599

b. Terdapat autokorelasi jika dU $<1.18$ atau $\mathrm{dL}>1.401$

Dari hasil perhitungan SPSS menunjukkan bahwa untuk submaximal test $d$ hitung Durbin Watson sebesar 1.864 dan aktivitas manual material handling sebesar 2.554, sehingga untuk 
kedua aktivitas tersebut tidak terjadi autokorelasi sehingga asumsi tidak adanya autokorelasi terpenuhi.

\section{Pengujian Homoscedasticity}

Pengujian ini dilakukan dengan membuat plot antara residu terhadap nilai prediksi variabel dependen VO2 max. Hasil SPSS menunjukkan bahwa error yang terjadi menyebar pada aktivitas submaximal test dan manual material handling. Selain itu tidak ada pola yang cenderung meningkat atau menurun, sehingga dapat disimpulkan bahwa tidak terdapat variansi error yang signifikan sehingga asumsi homoscedasticity terpenuhi (Adi dan Santraga, 2012).

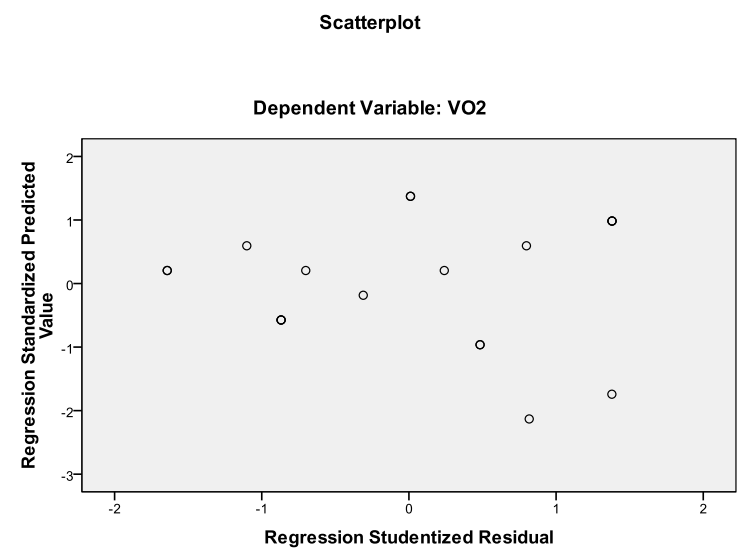

Gambar 8 Plot Normalitas residual Regresi Linier

5. Pengujian Multikolinieritas Antar Variabel Independen

Pengujian Multikolinearitas bertujuan untuk menguji model regresi apakah ada ditemukan korelasi antara variabel independen. Model regresi dinyatakan tidak ada multikolinearitas jika VIF (Variance Inflation Factor) tidak melebihi 10 dan nilai toleransi $>0.10$. Nilai VIF yang rendah akan menunjukkan kolinieritas yang rendah antar variabel independen. Hasil perhitungan menunjukkan VIF < 10(1.0) dan toleransi > 0.10 (1.0) untuk aktivitas submaximal test dan manual material handling.

\begin{tabular}{|c|c|c|c|c|c|}
\hline & & \multicolumn{2}{|c|}{ Submaximal test } & $\begin{array}{l}\text { manual } \\
\text { handling }\end{array}$ & material \\
\hline & & $\begin{array}{l}\text { Collinearit } \\
\text { Statistics }\end{array}$ & \multicolumn{2}{|c|}{ Collinearity } & Statistics \\
\hline Model & & Tolerance & VIF & Tolerance & VIF \\
\hline \multirow[t]{2}{*}{1} & (Constant) & & & & \\
\hline & HR & 1.000 & 1.000 & 1.000 & 1.000 \\
\hline
\end{tabular}

6. Intepretasi Hasil

Berdasarkan hasil perhitungan asumsi linearitas menggunakan metode stepwise maka terdapat satu variabel yaitu heart rate dengan nilai adjusted $\mathrm{R}^{2}$ sebesar 0.818 untuk 
aktivitas submaximal test dan 0.917 untuk manual material handling. Pada tabel 4 juga ditunjukkan nilai SSE (Standard Error of the Estimate) dimana semakin kecil nilai SSE maka akan semakin tepat pemodelan regresi linier dalam memprediksi nilai variabel dependen (Ghozali, 2005)

Tabel 4 Model Summary

\begin{tabular}{|c|c|c|c|c|c|}
\hline & \multicolumn{5}{|c|}{ Model Summary $^{b}$} \\
\hline & $\mathrm{R}$ & $\begin{array}{l}\text { Adjusted } \\
\mathrm{R}\end{array}$ & $\begin{array}{l}\text { Std. } \\
\text { Error of } \\
\text { the }\end{array}$ & Durbin- & \\
\hline $\mathrm{R}$ & Square & Square & Estimate & Watson & Jenis kegiatan \\
\hline $.910^{\mathrm{a}}$ & .828 & .818 & .21231 & 1.864 & Submaximal test \\
\hline $.960^{\mathrm{a}}$ & .921 & .917 & .10927 & 2.554 & $\begin{array}{l}\text { manual material } \\
\text { handling }\end{array}$ \\
\hline
\end{tabular}

Model regresi linier nantinya mempunyai nilai $R 2=91 \%$ ( Submaximal test ) dan $96 \%$ (manual material handling). Berdasarkan tabel 5 dapat dibuat persamaan regresi sebagai berikut :

a. $\mathrm{VO} 2 \mathrm{Max}=11.531-0.056$ heart rate (submaximal test)

b. $\mathrm{VO} 2 \max =23.910-0.141$ heart rate $($ manual material handling) dengan :

VO2 Max= Konsumsi Oksigen Maksimum ( liter/menit)

\begin{tabular}{|c|c|c|c|c|c|c|c|}
\hline \multicolumn{8}{|c|}{ Tabel 5 Hasil Persamaan Regresi Untuk Submaximal Test dan Manual Material Handling } \\
\hline & & \multicolumn{2}{|c|}{$\begin{array}{l}\text { Unstandardized } \\
\text { Coefficients }\end{array}$} & \multirow[t]{2}{*}{$\begin{array}{l}\text { Standardized } \\
\text { Coefficients }\end{array}$} & \multirow[b]{3}{*}{$\mathrm{t}$} & \multirow[b]{3}{*}{ Sig. } & \multirow[b]{3}{*}{ Kegiatan } \\
\hline & & & $\overline{\text { Std. }}$ & & & & \\
\hline \multicolumn{2}{|l|}{ Model } & $\mathrm{B}$ & Error & Beta & & & \\
\hline \multirow[t]{2}{*}{1} & (Constant) & 11.531 & .978 & & 11.793 & .000 & $\overline{\text { Submaximal }}$ \\
\hline & HR & -.056 & .006 & -.910 & -9.059 & .000 & Test \\
\hline \multirow[t]{2}{*}{2} & (Constant) & 23.910 & 1.319 & & 18.125 & .000 & Manual \\
\hline & HR & -.141 & .010 & -.960 & -14.110 & .000 & $\begin{array}{l}\text { Material } \\
\text { Handling }\end{array}$ \\
\hline
\end{tabular}

\section{KESIMPULAN DAN SARAN}

\section{Kesimpulan}

Dari hasil dan pembahasan yang dijelaskan diatas maka dapat diambil kesimpulan sebagai berikut :

a. Pada penelitian ini $80 \%$ mahasiswi bekerja di elektronika sedangkan sisanya di bidang lain dengan rata-rata mahasiswi yang bekerja memiliki 0-3 tahun pengalaman bekerja. 
b. Submaximal test selama 8 menit dan manual material handling termasuk kegiatan kerja pekerjaan ekstrim berat.

c. Terdapat korelasi antara konsumsi VO2 maksimum dengan heart rate sehingga menghasilkan persamaan VO2 Max $=11.531-0.056$ heart rate (submaximal test) dan VO2 $\max =23.910-0.141$ heart rate $($ manual material handling)

\section{Saran}

Adapun saran yang dapat diberikan oleh peneliti adalah sebagai berikut:

a. Pada perusahaan industri elektronika diharapkan dapat mempertimbangkan kemampuan fisik pekerjaan jika pekerja diberikan pekerjaan dengan beban kerja diatas batas kemampuan fisik dan diberikan waktu istirahat agar kondisi tubuh dapat kembali normal

b. Penelitian dapat dilanjutkan dengan mengaplikasikan persamaan prediksi tersebut di perusahaan industri elektronika untuk melihat tingkat eror antara actual konsumsi VO2 dan persamaan prediksi VO2 max.

\section{REFERENSI}

Hasibuan, Malayu S.P. 2005. Manajemen Sumber Daya Manusia, Edisi Revisi. Bumi Aksara, Jakarta.

Irdiastadi H. Yassierli.2014.Ergonomi Suatu Pengantar.PT.Remaja Rosdakarya;Bandung

Purnawan AW. Sangtraga HA. 2012. Pengembangan Persamaan VO2 dan Evaluasi HR Max (Studi Awal Pada Pekerja Pria).J@TI Undip. Vol.VII .No.1. Januari 2012

Soleman A. 2009. Kapasitas Aerobik Maksimum dan Persamaan Prediksi Konsumsi Oksigen Pada Perempuan Pekerja Industri.Tesis ITB 2009

Sukawati SY. 2010 Nilai VO2max Mahasiswa Kobe Jepang Lebih Tinggi daripada Mahasiswa Fakultas Kedokteran Universitas Sebelas Maret Surakarta.Skripsi. UNS

Yuliani.E.N.2010. Studi Penentuan kapasitas aerobic dan Persamaan ongkos metabolic pekerja industri. Tesis Magister. 